\title{
ASPECTOS GENERALES DE LA EMIGRACION ESPAÑOLA A AUSTRALIA
}

Australia, país lleno de grandes posibilidades en todo orden de cosas; tiene puestas un buen número de sus esperanzas como nación en la inmigración ${ }^{1}$ y de manera especial en la inmigración europea. Pero a su vez, tal aspiración australiana, de echar los cimientos de su población con un contingente humano típicamente europeo, se ve correspondido, por el deseo, cada vez mayor, de muchos páses latinos - entre los cuales se encuentra España- de establecer una corriente emigratoria hacia aquel continente, siempre, naturalmente, atemperada por las necesidades demográficas de las respectivas naciones de emigración. Varias son las razones que determinan a un grupo numeroso de habitantes de Europa, a abandonar su patria marchar a Australia: de una parte, la lejanía del país desconocido por la mayoría - les hace pensar en una aventura llena de atractivos, fuente tradicional de móvil migratorio. En realidad, Australia, no es a la manera de América hace algunos siglos, propicia a ninguna clase de aventuras y su alto grado de civilización y de civismo, se opone a toda forma irregular de vida, y lo que es más, a un ascenso social excesivamente rápido o al enriquecimiento inopinado. Por otro lado, su situación geográfica, que la mantiene, hoy por hoy, alejada de los puntos centrales de futuros y posibles conflictos mundiales, hace pensar a muchos en ella, como en una especie de refugio contra todos los desasosiegos y tiranteces que se padecen diariamente en nuestra vieja Europa: diríase que es el rincón ideal para los que se ha llamado con una terminología muy expresiva, los «Europamúde», los cansados de Europa. En este aspecto, hay muchos motivos para creer que tienen

* «Una continua inmigración, en el plano más elevado posible, es vital para la obtención de una plena seguridad, un más alto nivel de vida y un perfecto desarrollo social y económicon. Punto primero de la Carta de las Associated Chambers of manufacturers . 
razón los que as piensan. Finalmente la inmensidad del territorio, unido a la débil presión demográfica, da pie para imaginar justificadamente, en muchas más posibilidades de trabajo gue en otros páses del mundo.

Creenos sinceramente, que muchos de los sueños de los emigrantes a Australia podrán realizarse en casi su totalidad, pero ello no nos ha de hacer ver en aquel inmenso territorio, una especie de terra sin problemas, donde por el simple hecho de instalarse, todas las dificultades se allanarán repentinamente. De aquí que sea necesario orientar la opinión pública -como lo vienen ya haciendo nuestros organismos oficiales en materia migratoriaen un sentido totalmente objetivo, que evite toda desilusión, de difícil solución posterior en la mayoria de los casos.

Combinando parte de lo que hemos visto durante nuestra reciente estan. cia en aquel pais, con la información obtenida en diversas y documentadas publicaciones, trataremos de presentar algunos de los numerosos aspectos de la emigración española a Australia.

En aras de la mayor precisión esbozaremos las cuestiones más destacadas, a nuestro juicio al menos, con el siguiente orden: A) problemas de selección: tipo de emigrante más apropiado; emigración familiar y emigración femenina. B) Nivel de vida y C) Dificultades principales que se le presentan al emigrante.

A) Quizá una de las cuestiones más delicadas de la emigración española a Australia sea la selección, por los organismos nacionales, de los futuros emigrantes. Sin duda son muy diversos los intereses contrapuestos: intereses australianos, de llevarse una población adecuada -lógico desde su punto de vista; intereses españoles, de no quedarnos con una población carente de condiciones para nuestro rápido desarrollo industrial y agricola. Pero además se encuentra la oposición entre los intereses del individuo -que desea emigrar- y los del Estado, que por razones de bien común, limita tales deseos. No en vano se ha dicho que «la emigración pone en presencia dos ideas contradictorias: el derecho para el individuo de disponer de su propia persona y el derecho para el Estado de impedir la despoblación de su territorio». Una selección correcta ha de tener en cuenta lo más exactamente posible, tanto las necesidades del país de origen, como las posibilidades de éxito de los futuros emigrantes, pues sería tristemente perjudicial, enviar una serie de personas, que por su profesión, estado familiar u otras diversas causas, tuviesen que experimentar un rotundo fracaso en aquel país, dada su manera económica, social y humana de ser. Afortunadamente, tal selección viene siendo hecha de manera minuciosa por uuestro Estado, evitando así las consecuencias nefastas de una actuación poco cuidada.

Una de las primeras cuestiones que pueden plantearse es la siguiente: iinteresa en Australia, más bien personal cualificado o por el contrario sería más conveniente o aceptable la emigración de peonaje? Indudablemente no cabe una respuesta categórica y absoluta, pues hay que tener en cuenta las diversas circunstancias de cada momento, pero en principio plede decirse que la 
segunda clase de emigrantes son bien admitidos y tienen enormes poribilidades - siendo jóvenes y fuertes, como lo son-w en labores del campo te incluso de la industria. La ventaja para ellos es que no ballarán dificultad en trabajos duros y bien pagados por ello, tales como recoleccion, corte de caña, obras públicas etc. En cuanto a labores en empresas con técnicas especializadas, muchas prefieren, según hemos observado, personas sim gran preparación profesional, para darles esta, de una manera progresiva $y$ adecuada a la misión que se les va a encomendar. Pese a que un sector australiano, propugna por la introducción en aquella nación de personal cualificado, nuestras observaciones de la realidad social e industrial, nos hacen pensar en que una emigración de peonaje es altamente util alli y ventajosa para los interesados, a la vez que evitará una posible disminución de nuestros cuadros de personal especializado en las induscrias españolas. Quiza el ideal en esta materia, sería como señaló Mrs. Ferber, desde el punto de vista australiano, "obtener simplemente el mejor uso de las habilidades de nuestros emigrantes» ${ }^{2}$. Lo que parece más claro, es que un personal de preparación más bien burocrática o comercial, o incluso profesionales - tales como empleados de oficina, dependientes, médicos etc.- tiene dificultades para dedicarse a su propia función, de un lado por el idioma que es distinto y de otro por hallarse los puestos de tipo administrativo cubiertos por los australianos, siendo la revalidación de títulos, posible, pero muy costosa, en la generalidad de los casos. Su adaptación a labores manuales, suele resultar bastante dificultosa, por no hallarse acostumbrados a tal género de trabajo.

En segundo lugar se puede considerar la cuestión de si será más conveniente la emigración de solteros o por el contrario de grupos familiares. En un estudio presentado por W. D. Borrie a la Australian Citizenship Convention de 1960 , titulado "Should inmigration policy be directed primarly to obtaining a high ration of workers for industry or should it be directed to family inmigration?», se señala que hasta 1945 más bien se prefería solteros o casados sin hijos - porque sin duda preocupaba más el problema de la producción que el de la población - pero que hoy se da preferencia a la emigración familiar conjunta y así existe un programa de aumentar la población en un 2 por 100 anulal, debiendo ser la mitad de este porcentaje procedente de la emigración. Desde nuestro punto de vista, si bien es verdad que la emigración de núcleos familiares completos tiene más defensas, sin embargo nos parece más apropiada la solución intermedia, ya considerada por el Estado español, esto es, la emigración de personas aisladas - mejor solteros, para evitar disgregaciones familiares de consecuencias a veces malas- y la reagrupación familiar posterior, cuando el emigrante inicial, se haya abierto camino y encontrado casa, pues también ha llegado a aquellas tierras el problema de la habitación. Con esto se obtendrian las ventajas de

2 Report of Mrs. D. Ferber to A. F. U. W. en la Citizenship Convention de 1956. 
la emigración familiar y se evitarín los inconvenientes que se encuentran en un país hasta orientarse en él con cierta soltura.

Finalmente, nos queda en esta primera parte, hacer una ligera referencia a la emigración femenina, de mujeres solteras. Es cierto que la balanza de sexos en Australia está francamente desequilibrada y escasea extraordinariamente el sexo débil. En este sentido las facilidades de matrimonio son numerosas y Australia desea el aumento de la población infantil, que al fin y al cabo es fuente de verdaderos australianos. Pero existen en cambio otras circunstancias que han de hacernos sopesar mucho tal emigración femenina. El proceso seguido por un núcleo importante de mujeres solteras - españolas y de otros paises- es el siguiente: en principio van como servidoras domésticas y en calidad de tales obtienen colocación. El ambiente familiar suele serles muy favorable. El trato como norma general es excelente y sus ingresos oscilan de 9 a 12 libras por semana. Pero esta situación no suele durar mucho, debido a que tales jóvenes, con una aspiración muy comprensible, desean, de una parte, menos sujeción y de otra, mayor sueldo. Es a partir de este momento, cuando abandonan las familias a que fueron encomendadas y se van a las fábricas, con ingresos notablemente superiores. Para compensar los gastos de manutención y vivienda que antes no debían costear, se suelen unir en grupos de tres o cuatro y alquilan un apartamento, donde viven juntas, en circunstancias materiales muy buenas. Ahora bien, en el momento en que pierden el control familiar - que puede ser a veces escaso, pero de alguna influencia- se enfrentan con el gran problema de la administración de la libertad de que gozan, cosa nada fácil en un ambiente tan distinto del español. Con ello, se quiere dar a entender que se hallan expuestas a riesgos numerosos, que ha hecho preguntarse -quizá un poco inocentemente a la propia prensa australiana-, por qué los padres europeos no ven con muy buenos ojos que sus hijas vayan solas a Australia. Uno de los medios de paliar tales peligros es naturalmente una asistencia religiosa adecuada y de manera especial con sacerdotes españoles, que en la actualidad no hay en Australia, al menos hasta hace muy pocos meses, pues si bien un grupo de sacerdotes australianos ponen todo su celo en cuidar a nuestros emigrantes espiritualmente, sin embargo, parte, por la mentalidad distinta y parte por el idioma, su labor ímproba se ve a veces limitada. El número de españoles de ambos sexos en Australia, según declaraciones del Ministro de Inmigración era en marzo de 1960 de $2.000^{3}$, número ligeramente aumentado en la actualidad. Quizá con pocos sacerdotes en cada una de las ciudades importantes se pudiera resolver gran parte del problema de orientación y asistencia religiosa.

B) Pasemos ahora a considerar el nivel de vida. Es imposible dejar de reconocer que es muy alto, a veces ciertamente asombroso. Haciendo un

3 The infiuence of migration on Australian foreign policy. The Roy Milne Lecture for 1960. 
resumen de los datos principales obtenidos en enero de $1960^{~ "}$ " expondremos los siguientes:

El salario minimo oscila entre 12 libras y 18 chelines y 14 libras y 3 chelines, por semana. Tal salario pernite vivir normalmente, si bien es corriente que nuestros emigrantes ganen mucho más, al poco tiempo de estancia en el país.

La jornada de trabajo es de 40 horas semanales.

El problema de la habitación, plantea dificulades, aunque es distinto del nuestro, pues el 63 por ciento de la población habita en casa propia, generalmente pequeños chalets. De aquí que mientras el emigrante obtiene el suficiente dinero para comprarse una casita, que costará al menos 625 libras, deberá vivir en apartamentos, que generalmente constan de una sala, dormitorio, cocina y bañó común. La renta de un piso oscila entre 1 libra y 10 chelines y 3 libras por semana. Además la buena organización de los servicios de inmigración permite otra solución en esta materia: consiste en permanecer en un Centro de Recepción para emigrantes, tales como el de Boneguilla, verdadero pueblo con capacidad para cinco mil personas, que permite alojarse en casas especialmente preparadas, a la familia del emigrante en tanto en cuanto aquél que se logra independizar económicamente. Las condiciones de tales centros son excelentes: cuentan con todo lo necesario, desde asistencia religiosa de casi todos los credos, hasta bibliotecas, teatros, hospitales, «kindergarten», piscinas, campos de deporte, etc. El «Reception and Training Centre» de Boneguilla, al que acabamos de referimos, es un modelo en su género y su organización es verdaderamente perfecta.

Como datos significativos del alto nivel de vida recogemos las siguientes cifras: En 1959 existía un vehículo de motor por cada cuatro habitantes. Televisiones, en 1960, una por cada diecisiete habitantes, teléfonos uno por cada cinco habitantes y así aproximadamente en todos los artículos de comodidad o ayuda casera

Si la felicidad dependiera exclusivamente del número de coches o televisiones, que se posean, bien podriamos decir que los australianos han llegado a la felicidad casi total, sin embargo, es necesario ver estas cifras con objetividad y pensar que todas esas cosas que aún en España sirven casi solo de solaz y recreo alli son meros instrumentos de trabajo. El coche por ejemplo -ideal de tantos españoles- se utiliza en la mayoría de los casos para ir y venir del trabajo, que se suele encontrar fácilmente a 40 ó 50 millas de distancia de la propia casa.

Ha habido españoles que han manifestado, que notaban Australia triste. Quizá tengan razón, visto desde nuestro ángulo español: nuestras terrulias de café, nuestras peñas de amigos, el paseo familiar del domingo de la generalidad de las provincias españolas, las terrazas de nuestros establecimientos de hostelería, son desconocidas en Australia. La vida es excesivamente rápida.

4 Estos datos están tomados de Australia, in brief», publicación oficial. 
W horario mismo impulsa al ciudadano a estar siempre pendiente del reloj. Sin embargo, como es râuzal, aquellas gentes también se divierten: tienen sus clubs, beben serveza -aunque con límite de tiempo-van a sus carreras de caballos y practican mucho más el deporte que nosotros. Es de esperar que el español se adapte poco a poco a aquella nueva forma de emplear sus ocios, si bien le será más diffíl acostumbrarse a la velocidad de la vida, por tener una filosofia -llanémosla asi- distinta de la de aquel pueblo, no se si más o menos acertada, que le hace pensar en términos muy semejantes a los de un conocido poeta inglés:

\author{
What is the life, \\ if tull of cares, \\ we have no time \\ to stand and stare. \\ To stand beneath the bows \\ and stare as long as sheep and cows?
}

Todos estos datos no han de desilusionar ni mucho menos a los futuros emigrantes, puesto que en todo caso nunca el objeto de emigrar ha sido divertirse; sino en realidad vivir mejor y esto es seguro, que desde ún punto de vista material, lo conseguirán en la mayoría de los casos, mucho más cuando el aprecio y elogio de que son objeto nuestros emigrantes en Australia, es general, tanto en las esferas privadas, como públicas.

C) Veamos abora las tres dificultades principales con que se ha de encontrar nuestro emigrante: el idioma, la asimilación al país y la mentalidad distinta.

a) No saber un idioma en país extranjero es algo así como estar casi sordo y mudo. Sin duda esto es duro y tal situación viene agravada si se tiene en cuenta que por razones diversas, el anglosajón cree en un principio que considera incontrovertible: que todo el mundo debe saber expresarse correctamente en inglés. $Y$ así como el español, se esfuerza por entender al extranjero, el australiano no se caracteriza generalmente por dar facilidades. Quiere que se hable inglés -o mejor aún- australiano, pues hay diferencias notables. Este desconocimiento del idioma aisla indudablemente al prin. cipio a nuestros emigrantes, pero el Gobierno australiano se esfuerza por dar todo género de facilidades en materia de educación y la labor del «Council of Adult Education», es eficacísima, pudiéndose decir que la mayoría de los emigrantes asisten a clases de tarde, de inglés que en el plazo de un año les permitirán incorporarse a una conversación normal, sin ninguna dificultad.

b) El segundo problema es el de la asimilación al país. Es a veces difícil a un hombre de más de veinte años adaptarse inmediatamente a una nación tan distinta de la nuestra y de lo latino en general. El gobierno australiano sin embargo propugna la asimilación y desea en la medida de lo posible verdaderos australianos. La realidad es que, como seăalaron los Sres. Mas- 
sero ${ }^{5}$, todo milita al principio en contra de la asimilación: los prejuicios, el idioma, la soledad, la nostalgia, etc. En general se trata de evitar la creación de grupos nacionales que impidan la realización de auténticos ciudadanos australianos. En un interesante informe de Mr. Prices, se hace referencia a los tres grupos típicos que dificultan la asimilación: las llamadas achaira inmigrations», esto es aquellas migraciones formadas por personas que una vez establecidos en el país llaman a sus amigos y parientes para formar colonia; los "gravitation groups», constituidos por aquellos emigrantes que una vez concluidos sus compromisos con empresas, entidades, etc., donde trabajaron, se concentran en un punto determinado, para reunirse con sus compatriotas y trabajar aislados de todo contacto con el macional y finalmente los «compression groups», originados cuando la hostilidad de los ciudadanos del pais hacen unirse, para protegerse entre si, a los emigrantes. Este último grupo no cabe en Australia. El español es más bien individualista y como norma general no se trata más que con un número muy reducido de compatriotas y con muy pocos australianos.. Es muy probable que tan pronto como vayan adquiriendo conocimientos del idioma, aumenten sus relaciones con los que les rodeen.

c) Por último, el obstáculo mayor con que han de luchar nuestros emigrantes es la mentalidad distinta. Los numerosos rasgos de espiritualidad que afortunadamente se ven aun hoy en Europa, se dan bastante menos en Australia. El materialismo es creciente y el dinero parece la única aspiración de la mayoría. La moral se halla un tanto resquebrajada, si bien, se mantienen las buenas formas ciudadanas y el civismo es profundmente llamativo. El respeto al próiimo es extraordinario en cualquier manifestación social. Es pena que países como este, con un nivel de vida tan elevado, hayan llegado, quizá por eso mismo, a una especie de confianza excesiva en las fuerzas de la propia persona, con perjuicios de todo orden, en la esfera familiar -que tiende a disgregarse- y en la religiosa, que hace que se separe la religión de la vida, transformándola en una especie de objeto de especulación o de pura reflexión, en el mejor de los casos. Se «han cortado las raíces espirituales de la vida» y ésta por sí misma, vive precarianente. Recuerdo un artículo de un periódico de Melbourne, escrito según creo, por una francesa, cuyo título era harto significativo: «Australia, país sin alma». Materialmente es una tierra ideal, pero el europeo echa en falta alli algo que le es necesario para vivir y que solo puede dar una serie de siglos de reservas espirituales e ideológicas. Si quisiéramos reflejar este ambiente con más exactitud lo diríamos con palabras de J.A.C. Brown ${ }^{7}$ : «Por doquier vamos viendo en este mundo moderno ejemplos de un verdadero y curioso hedonismo pervertido: la generalidad de la gente cree que lo que necesita

Understanding: the key of assimilation. Informe al A. C. C., 1960.

The social consequences of the present distribution of nationalities, 1960.

The social psychology of industriy.-A. Pelikan Book, pág. 278. 
es más dinero, más píldoras, nás radios y en general más cosas. Piensan que cuanto mayor numero de objetos materiales se puedan obtener o reunir por nada, wás felices serán. Y desde luego, si la gente necesita estas cosas, no hay razón para no darselas. Pero constituye un serio error, intentar satisacer a hombres y mujeres con lo que no son sino meros complementos de la felicidad, mientras que ignotan sus necesidades más fundamentales...».

Es de esperar que los españoles - que más de una vez se han enfrentado con este genero de dificulades-sepan sobreponerse a este ambiente de materialsmo, que por desgracia también se respira ya en Europa.

FeLIPE VAZQUEZ MATEO

Inspector Técnico de Trabajo 